ARTICLE

\title{
Dopamine $\mathrm{D}_{3} \mathrm{R}$ antagonist VK4-116 attenuates oxycodone self-administration and reinstatement without compromising its antinociceptive effects
}

\author{
Zhi-Bing You ${ }^{1}$, Guo-Hua Bi ${ }^{1}$, Ewa Galaj ${ }^{1}$, Vivek Kumar ${ }^{1}$, Jianjing Cao ${ }^{1}$, Alexandra Gadiano ${ }^{1,2}$, Rana Rais ${ }^{2}$, Barbara S. Slusher ${ }^{2}$, \\ Eliot L. Gardner ${ }^{1}$, Zheng-Xiong $\mathrm{Xi}^{1}$ and Amy Hauck Newman (iD)
}

Prescription opioids such as oxycodone are highly effective analgesics for clinical pain management, but their misuse and abuse have led to the current opioid epidemic in the United States. In order to ameliorate this public health crisis, the development of effective pharmacotherapies for the prevention and treatment of opioid abuse and addiction is essential and urgently required. In this study, we evaluated-in laboratory rats-the potential utility of VK4-116, a novel and highly selective dopamine D3 receptor (D3R) antagonist, for the prevention and treatment of prescription opioid use disorders. Pretreatment with VK4-116 (5-25 mg/kg, i.p.) dose-dependently inhibited the acquisition and maintenance of oxycodone self-administration. VK4-116 also lowered the breakpoint (BP) for oxycodone self-administration under a progressive-ratio schedule of reinforcement, shifted the oxycodone dose-response curve downward, and inhibited oxycodone extinction responding and reinstatement of oxycodone-seeking behavior. In addition, VK4-116 pretreatment dose-dependently enhanced the antinociceptive effects of oxycodone and reduced naloxoneprecipitated conditioned place aversion in rats chronically treated with oxycodone. In contrast, VK4-116 had little effect on oral sucrose self-administration. Taken together, these findings indicate a central role for D3Rs in opioid reward and support further development of VK4-116 as an effective agent for mitigating the development of opioid addiction, reducing the severity of withdrawal and preventing relapse.

Neuropsychopharmacology (2019) 44:1415-1424; https://doi.org/10.1038/s41386-018-0284-5

\section{INTRODUCTION}

Prescription opioids, such as oxycodone and morphine, are effective analgesics in clinical pain management. Nevertheless, in addition to the side effects of these drugs-including respiratory depression and constipation-one of the more serious adverse consequences is potential opioid abuse and addiction following repeated use. Indeed, the dramatic increase in prescription opioid use and abuse has lead to significant increases in emergency room visits, drug-related deaths, and admissions to substance-abuse treatment programs, each imposing a significant impact on public health and economic welfare [1-3]. It is estimated that 11.5 million Americans used prescription opioids nonmedically in 2016 and $80 \%$ of the population suffering from opioid use disorders were prescription opioid abusers [1]. This rise in prescription opioid misuse and abuse is also associated with an increased rate of transition to the abuse of heroin, an illicit opioid sharing similar pharmacologic actions with prescription opioids [1, 4]. Further, the illicit (and in some cases unsuspected) ingestion of the highly potent opioid fentanyl has resulted in an increased propensity to overdose [5]. Thus, understanding the mechanisms underlying the reinforcing effects of opioids that lead to addiction, and the development of effective treatments for affected individuals is critical.
Compelling evidence from animal studies suggests the involvement of dopamine D3 receptors (D3Rs) in the development of addictive behaviors caused by many drugs of abuse, including the illicit opioid heroin [6, 7]. Blockade of D3R with selective D3R antagonists has been shown to significantly inhibit psychostimulant self-administration [8,9], conditioned place preference (CPP) to drugs of abuse [10-14], and reinstatement of drug-seeking behavior triggered by addictive drugs [14-16], stress [17], or drugassociated cues $[13,18-20]$. D3R blockade also inhibits locomotor sensitization and the enhanced brain stimulation reward induced by drugs of abuse [20-23]. In contrast, D3R blockade shows little effect on natural rewards, such as sucrose self-administration and sexual activity $[14,20,23-25]$. These collective findings suggest that targeting the D3R is a highly promising approach for the treatment of substance use disorders.

Despite the involvement of D3R in drug addiction, the clinical translation remains challenging due to either the lack of appropriate absorption, distribution, metabolism, and excretion (ADME) properties or predicted cardiotoxicity of previously reported D3R antagonists in the presence of cocaine $[26,27]$. As a result of these limitations, efforts to develop a new generation of D3R agents that are devoid of these undesirable attributes have resulted in the discovery of the highly selective D3R antagonist, VK4-116 (D3R $K_{\mathrm{i}}=6.8 \mathrm{nM}$; D2R $\left.K_{\mathrm{i}}=11,400 \mathrm{nM}[28]\right)$.

\footnotetext{
${ }^{1}$ Molecular Targets and Medications Discovery Branch, National Institute on Drug Abuse, Intramural Research Program, Baltimore, MD 21224, USA and ${ }^{2}$ Department of Neurology, Johns Hopkins Drug Discovery, The Johns Hopkins University School of Medicine, Baltimore, MD, USA Correspondence: Zheng-Xiong Xi (zxi@mail.nih.gov) or Amy Hauck Newman (amy.newman@nih.gov)
}

Received: 31 July 2018 Revised: 12 November 2018 Accepted: 16 November 2018 Published online: 27 November 2018 
Herein, we systematically investigated the effects of VK4-116 on the acquisition and maintenance of oxycodone self-administration, extinction, and oxycodone-induced reinstatement of drugseeking behavior in rats. We also investigated the effects of VK4116 on oxycodone analgesia and naloxone-precipitated conditioned place aversion (CPA) in chronically oxycodone-treated rats to determine whether VK4-116 pretreatment compromises therapeutic opioid analgesia and/or alters withdrawal responses. Finally, we previously reported that VK4-116 showed metabolic stability in mouse liver microsomes [28]. In this report, we further investigated metabolic stability of VK4-116 in rat, monkey, and human liver microsomes to determine its translational potential.

\section{MATERIALS AND METHODS}

Animals

Male Long-Evans rats (275-325 g) (Charles-River Laboratories, Raleigh, NC, USA) were used throughout this study. Upon arrival, they were housed in an animal facility under a reversed $12 \mathrm{~h}$ light-dark cycle (lights on at 7 p.m.) with free access to food and water. They were allowed to acclimate to a new environment for at least 7 days prior to the start of the experiments. All procedures were approved by the Animal Care and Use Committee (IACUC) of the US National Institute on Drug Abuse (NIDA) and were consistent with the Guide for the Care and Use of Laboratory Animals, 8th edition (National Research Council, 2011).

Experiment 1: Effects of VK4-116 on acquisition of oxycodone selfadministration. The intravenous (i.v.) catheterization surgery and i.v. oxycodone self-administration procedures were the same as reported previously [24]. Briefly, a Micro-Renathane catheter was implanted in the right jugular vein under sodium pentobarbital $(65 \mathrm{mg} / \mathrm{kg}$, intraperitoneally (i.p.)) anesthesia. The catheter was secured to the vein with suture and its free end was fed subcutaneously along the scapula to exit near the back of the skull. Next, the catheter was connected to a 22-gauge stainless connector that was mounted to the rat's skull using stainless-steel screws and dental acrylic. After surgery, the catheters were flushed with a gentamicin-heparin-saline solution $(0.1 \mathrm{mg} / \mathrm{ml}$ gentamicin and $30 \mathrm{IU} / \mathrm{ml}$ heparin) to prevent catheter clogging and infection. The animals were allowed to recover for at least 5 days before behavioral training started.

Oxycodone self-administration training was conducted in an operant conditioning chamber equipped with two response levers (Med Associates Inc., Georgia, VT, USA). Each rat was trained daily in $3 \mathrm{~h}$ sessions to press the active lever for oxycodone infusions on a fixed-ratio 1 (FR1) schedule of reinforcement. A response on the active lever resulted in the activation of light and tone cues and the infusion of an $0.08 \mathrm{ml}$ oxycodone solution over $4.6 \mathrm{~s}$. This time also served as a timeout period during which the light and tone cues were kept on and the animal's response on the active lever was recorded but had no scheduled consequence. Each animal's response on the inactive lever was recorded but not rewarded throughout training and testing.

We then assessed the effects of repeated daily administration of VK4-116 on the acquisition of oxycodone self-administration maintained by $0.05 \mathrm{mg} / \mathrm{kg} /$ infusion for 5 consecutive days. The oxycodone dose and the VK4-116 treatment for 5 consecutive days were based on our previous report that oxycodone, at doses of $0.025,0.05$, and $0.1 \mathrm{mg} / \mathrm{kg} /$ infusion, sustained dose-dependent self-administration and that drug-naive rats took about 5 days to reach stable oxycodone self-administration [24]. Stable oxycodone self-administration was defined as (i) at least 20 active lever responses under an FR1 schedule of reinforcement during a 3-h session, (ii) $<20 \%$ variability in daily drug infusions across consecutive sessions, and (iii) an active/inactive lever press ratio exceeding 2:1 [29]. To prevent oxycodone overdose, we set the maximally permitted number of oxycodone infusions at 50 . Fifteen minutes before each of the initial five sessions, rats received either vehicle (25\% 2-hydroxypropyl- $\beta$-cyclodextrin) or one of two VK4116 doses (5 or $15 \mathrm{mg} / \mathrm{kg}$, i.p.), respectively. The animals then continued oxycodone self-administration for additional six sessions without VK4-116 pretreatment. Animals' responses on the levers and oxycodone infusions were recorded.

Experiment 2: Effects of VK4-116 on maintenance of oxycodone selfadministration. In addition to acquisition, we also observed the effects of VK4-116 pretreatment on maintenance of oxycodone self-administration. Four additional groups of rats ( $n=7 /$ group) were trained to self-administer oxycodone first at a higher dose $(0.1 \mathrm{mg} / \mathrm{kg} /$ infusion) for 2 weeks, and then were switched to a lower dose $(0.05 \mathrm{mg} / \mathrm{kg} /$ infusion) for the remaining training and test sessions. The initial higher dose was chosen on the basis of our previous experience that this dose produced the most rapid and facile acquisition of oxycodone self-administration. The subsequent lower dose of oxycodone was chosen in order to increase animals' work demand (i.e., lever presses) to achieve the same drug effect. In our experience, this approach increases sensitivity to changes in drug-taking or drug-seeking behavior [23]. After stable self-administration was achieved, the rats received either the vehicle or one of the three VK4-116 doses (5, 15 , or $25 \mathrm{mg} / \mathrm{kg}$, i.p.), $15 \mathrm{~min}$ prior to the test session. The effects of VK4-116 on oxycodone self-administration were assessed.

Experiment 3: Effects of VK4-116 on extinction responding. Following completion of the above self-administration testing, the rats continued to self-administer oxycodone $(0.05 \mathrm{mg} / \mathrm{kg} / \mathrm{infusion})$ for an additional four sessions. The next day, the animals were reassigned into three groups ( $n=7 /$ group) and received either the vehicle or one of the two doses of VK4-116 (5 or $15 \mathrm{mg} / \mathrm{kg}$ ). Fifteen minutes later, the animals were placed in the chambers to observe drug-seeking behavior (i.e., extinction responses) under extinction conditions, during which saline was substituted for oxycodone. Lever presses on the previously active lever produced saline infusions but had no other consequences-neither oxycodone infusions nor the conditioned lights and tones. The responses on the active and inactive levers, and a number of saline infusions were recorded.

Experiment 4: Multiple-dose oxycodone self-administration. To determine whether VK4-116 alters oxycodone self-administration maintained by other doses of oxycodone, we used additional groups of rats ( $n=7-8 /$ group) and evaluated self-administration of multiple oxycodone doses $(0.0031,0.00625,0.0125,0.025$, and $0.05 \mathrm{mg} / \mathrm{kg} /$ infusion) in the absence or presence of the VK4-116 pretreatment. The infusion volumes and test session durations were identical, except for different oxycodone concentrations at each unit dose. After stable oxycodone self-administration was achieved at each oxycodone dose tested, the animals received a systemic administration of VK4-116 (25 mg/kg, i.p.) or the vehicle 15 min prior to the self-administration session. The effects of VK4116 on the oxycodone dose-response curve were evaluated.

Experiment 5: Effects of VK4-116 on oxycodone self-administration under $P R$ reinforcement. Four additional groups of rats $(n=7$ per group) were used in this experiment. The initial oxycodone selfadministration training under FR1 reinforcement was identical to that outlined in the above Experiment 2. After stable oxycodone self-administration was established, the subjects were switched to a progressive ratio (PR) schedule of reinforcement, during which the work requirement (lever presses) needed to receive a single i.v. oxycodone infusion was progressively raised within each test session according to the following PR series: $1,2,4,6,9,12,15,20$, $25,32,40,50,62,77,95,118,145,178,219,268,328,402,492$, and 603 until a break-point (BP) was reached. BP was defined as the maximal work load (lever presses) completed for an oxycodone 
infusion before a 1-h period during which no infusion was obtained by the animal. Animals were allowed to continue daily sessions of oxycodone self-administration under PR reinforcement until the number of ration increments could vary by no more than two over three consecutive sessions. Once a stable baseline BP was established, subjects were assigned to four subgroups to determine the effects of vehicle and three different doses of VK4$116(5,15$, and $25 \mathrm{mg} / \mathrm{kg}$, i.p.) on PR BP. We chose a betweensubjects design for this experiment because it is relatively difficult to re-establish a stable BP level after each test under PR reinforcement.

Experiment 6: Effects of VK4-116 on oxycodone-triggered reinstatement of drug-seeking behavior. Following the completion of the experiments in Experiment 3, extinction sessions continued until the rats' average active lever presses/session decreased to $<10$ responses over three consecutive sessions. On the following day, two groups of rats were treated with 1 of the two VK4-116 doses ( 5 or $15 \mathrm{mg} / \mathrm{kg}$ ), while another group was treated with the vehicle. Fifteen minutes later, all animals received a non-contingent injection of oxycodone $(1 \mathrm{mg} / \mathrm{kg}$, i.p.) and then were placed into the same operant chambers for a drug-induced reinstatement test session [24]. Responses on the active and inactive levers were recorded. Lever response did not lead to any consequenceneither i.v. oxycodone infusion nor re-exposure to conditioned cue lights and tones during the reinstatement test.

Experiment 7: Effects of VK4-116 on naloxone-precipitated CPA. Naloxone-precipitated CPA was tested in a place-conditioning apparatus (Med Associates, St Albans, VT, USA) consisting of two compartments $(21 \mathrm{~cm} \times 28 \mathrm{~cm})$ and a central gray connecting area $(21 \mathrm{~cm} \times 12.5 \mathrm{~cm})$; sliding doors separated each compartment from the connecting area. The two side compartments differed in wall color (black vs. white), floor type (stainless-steel net vs. stainless-steel grid), and illumination. Before the experiment started, the animals were allowed to explore the conditioning apparatus for $15 \mathrm{~min}$ (preconditioning). Rats that displayed significant bias to one compartment over the other ( $\geq 200 \mathrm{~s}$ difference) during the preconditioning session were excluded from the study.

The procedures for naloxone-precipitated CPA were the same as reported previously [30,31]. Six groups ( $n=8 /$ group) of rats were used in this experiment. Three groups were chronically treated with oxycodone ( $3 \mathrm{mg} / \mathrm{kg}$, i.p.) and the other three groups were treated with saline $(1 \mathrm{ml} / \mathrm{kg})$, twice a day $(800$ and $1800 \mathrm{~h})$ for six and a half days. Four hours after the morning injections on days 4 and 6 , the oxycodone-treated rats were challenged with saline and immediately confined in one compartment of the place-conditioning apparatus for $30 \mathrm{~min}$. On days 5 and 7 , rats were first treated with either the vehicle or 1 of 2 doses of VK4-116 ( 5 or $15 \mathrm{mg} / \mathrm{kg}$, i.p.) $3 \mathrm{~h}$ after a morning oxycodone injection, and $1 \mathrm{~h}$ later, they were challenged with naloxone $(1 \mathrm{mg} / \mathrm{kg}$, i.p.). The rats were then immediately confined in the other compartment for $30 \mathrm{~min}$. The saline- or naloxone-paired compartments were counterbalanced in each group. Chronically saline-treated groups were subjected to the same place-conditioning procedures as oxycodone-treated groups: they were challenged with saline on days 4 and 6 and the vehicle or VK4-116 and naloxone on days 5 and 7. Twenty-four hours after the last conditioning session, the animals were each placed in the same apparatus and allowed to explore the apparatus for an additional $15 \mathrm{~min}$. The time the animals spent in each compartment was recorded. The CPA score was calculated as a difference in time spent in the drug-paired vs. the saline-paired compartment.

Experiment 8: Effects of VK4-116 on sucrose self-administration. The procedures for oral sucrose self-administration were identical to those for oxycodone self-administration, except that active lever presses led to a delivery of $0.08 \mathrm{ml}$ of $5 \%$ sucrose solution into a liquid food tray located on the operant chamber wall. Seven rats were used for sucrose self-administration training and testing. Sucrose deliveries were capped at 100 per session to prevent food satiation and a reduction in motivation for sucrose-taking behavior. After training, the animals were tested three times under vehicle treatment or one of two doses of VK4-116 (15 or 25 $\mathrm{mg} / \mathrm{kg}$, i.p.). The treatment was counterbalanced for each rat and each test was separated by two additional training sessions. The total number of sucrose deliveries during the 3-h self-administration session, the time spent to earn the total sucrose deliveries, and the rates of sucrose deliveries as calculated by total sucrose deliveries/time spent ( $\mathrm{min}$ ) were used to evaluate the effects of VK4-116 on sucrose self-administration.

Experiment 9: Effects of VK4-116 on oxycodone-induced antinociceptive response. Nociceptive tests were performed using a hot plate device (Model 39, IITC Life Science Inc., Woodland Hills, CA, USA). The rat was placed inside a transparent cage on the hot plate $\left(52 \pm 0.2^{\circ} \mathrm{C}\right)$. When thermal nociceptive signs such as licking, stomping the hind paw, or jumping from the plate appeared, the rat was immediately removed from the cage. The time interval (s) from rat being placed on the hotplate to exhibiting the first sign of thermal nociception was measured. The cutoff time for the test was $60 \mathrm{~s}$ to avoid tissue damage.

These experiments involved eight groups of rats $(n=8-9$ / group) in two series of repeated testing: four groups were used to test the effects of VK4-116 on antinociception induced by a single dose of oxycodone. Four additional groups were used to test the effects of VK4-116 on antinociception induced by the various oxycodone doses. Each rat was first habituated to the testing environment for $1 \mathrm{~h}$, followed by placement on the hot plate without treatment to obtain baseline response latencies. The groups in the time-course test were tested for 2 consecutive days. On the first day, group 1 was pretreated with the vehicle, and the other three groups were pretreated with a VK4-116 dose $(5,15$, or $25 \mathrm{mg} / \mathrm{kg}$, i.p.). Fifteen minutes following the pretreatment, each rat was challenged with a saline injection $(1 \mathrm{ml} / \mathrm{kg})$ and, $30 \mathrm{~min}$ later, tested on the hot plate. The next day, each group received the same pretreatment as on day 1, but was challenged with an oxycodone injection $(2 \mathrm{mg} / \mathrm{kg}$, i.p.). Each rat was then tested repeatedly at 30,60 , and 120 min following the oxycodone challenge injection. For the oxycodone dose-response curve determination, the animals were tested for 4 consecutive days, with the same pretreatment regimen on each day, but were challenged with ascending oxycodone doses $(0.5,1,2$, or $4 \mathrm{mg} / \mathrm{kg}$, for day $1,2,3$, and 4 , respectively). The hot plate test was conducted 30,60 , and 120 min after each oxycodone challenge injection on each day. Data were calculated as \% of maximum percentage effect (\% MPE) using the formula: (treatment valuebaseline value)/(cutoff value -baseline value) $\times 100$. The doses of oxycodone and the time points for the hot plate test were chosen based on reports that the peak effect of oxycodone appeared approximately $30 \mathrm{~min}$ following injection, and the chosen oxycodone doses produced a full range of effects in the hotplate test $[32,33]$.

Experiment 10: Microsomal stability assays. Phase I metabolic stability assays were conducted in rat liver microsomes purchased from BD Gentest (San Jose, CA, USA), rhesus monkey microsomes from XenoTech LLC (Lenexa, KS, USA), and human liver microsomes from Corning Gentest (Woburn, MA, USA), as we have previously described [28]. Briefly, the reaction was carried out with $100 \mathrm{mM}$ potassium phosphate buffer, $\mathrm{pH} 7.4$, in the presence of a reduced form of nicotinamide adenine dinucleotide phosphate (NADPH)-regenerating system (1.3 mM NADPH, $3.3 \mathrm{mM}$ glucose-6phosphate, $3.3 \mathrm{mM} \mathrm{MgCl}, 0.4 \mathrm{U} / \mathrm{ml}$ glucose-6-phosphate dehydrogenase, $50 \mu \mathrm{M}$ sodium citrate). Reactions in triplicate were 


\section{8}

initiated by the addition of the liver microsomes to the incubation mixture (final concentration of VK4-116 was $10 \mu \mathrm{M} ; 0.5 \mathrm{mg} / \mathrm{ml}$ microsomes). Percent VK4-116 remaining as a function of time was monitored via liquid chromatography with tandem mass spectrometry. The half-life $\left(t_{1 / 2}\right)$ of compounds' metabolic stability from liver microsomes was estimated using the first-order equation $t_{1 / 2}=0.693 / K_{\mathrm{el}}$, where $K_{\mathrm{el}}$ (elimination rate constant) is the slope of linear regression from natural log percentage substrate remaining vs. incubation time [34].

Chromatographic analysis was performed using an Accela ${ }^{\mathrm{TM}}$ ultra high-performance system consisting of an analytical pump, and an autosampler coupled with TSQ Vantage mass spectrometer (Thermo Fisher Scientific Inc., Waltham, MA, USA). Separation of the analyte was achieved at ambient temperature using the Agilent Eclipse Plus column $\left(100 \times 2.1 \mathrm{~mm}^{3}\right.$ i.d. $)$ packed with a $1.8 \mu \mathrm{m}$ C18 stationary phase. The mobile phase was composed of $0.1 \%$ formic acid in acetonitrile and $0.1 \%$ formic acid in $\mathrm{H}_{2} \mathrm{O}$ with gradient elution. The total run time for each analyte was $4.5 \mathrm{~min}$. The $[\mathrm{M}+\mathrm{H}]^{+}$ion transitions of VK4-116 (m/z 143.930, 213.003) and the internal standard $(\mathrm{m} / \mathrm{z} 423.03>180.086,207.086)$.

\section{Drugs}

VK4-116 [( \pm )-N-(4-(4-(3-chloro-5-ethyl-2-methoxyphenyl)piperazin1-yl)-3-hydroxybutyl)-1H-indole-2-carboxamide] was synthesized according to the published procedure [28]. Oxycodone $\mathrm{HCl}$, sucrose, and 2-hydroxypropyl- $\beta$-cyclodextrin were purchased from Sigma/RBI (St Louis, MO, USA). Oxycodone was dissolved in physiological saline for either i.v. infusions or i.p. injections. 2-Hydroxypropyl- $\beta$-cyclodextrin as a vehicle for VK4-116 was dissolved in water to achieve a concentration of $25 \%$.

\section{Data analyses}

All behavioral data are presented as means \pm SEM. One-way or two-way analyses of variance (ANOVAs) for repeated measures over time were used to analyze the data across the experiments. Post-ANOVA multiple comparisons were carried out using the Newman-Keuls test. $P<0.05$ was considered to indicate statistical significance.

\section{RESULTS}

VK4-116 pretreatment blocks acquisition of oxycodone selfadministration

Figure $1 \mathrm{a}, \mathrm{b}$ show mean $( \pm \mathrm{SE})$ oxycodone infusions and active lever presses across self-administration sessions in three groups of rats that were pretreated with vehicle, $5 \mathrm{mg} / \mathrm{kg}$, or $15 \mathrm{mg} / \mathrm{kg}$ VK4116 during the initial five sessions. Pretreatment with VK4-116 dose-dependently inhibited the acquisition of oxycodone selfadministration as indicated by reductions in oxycodone infusions and active lever presses. After termination of the VK4-116 treatment, the number of oxycodone infusions and active lever responses remained significantly lower during subsequent selfadministration sessions (sessions 6-8), and gradually increased thereafter to approximately similar levels as seen in the vehicletreated group. A two-way ANOVA with sessions as the repeatedmeasures factor and treatment group as the between-subjects factor revealed significant main effects of VK4-116 treatment (a, $F_{2,21}=10.59, p<0.001 ; b, F_{2,21}=10.22, p<0.001$ ) and session (a: $F_{10,210}=5.48, p<0.001 ;$ b: $\left.F_{10,210}=4.39, p<0.001\right)$. Pretreatment with VK4-116 showed no effects on the rats' responses on the inactive lever (data not shown), suggesting that their general behavior was not disrupted.

VK4-116 inhibits maintenance of oxycodone self-administration After stable self-administration was achieved in additional groups of rats, each animal received vehicle or one of the VK4-116 doses $(5,15$, and $25 \mathrm{mg} / \mathrm{kg}$, i.p.), respectively. Pretreatment with VK4-116 dose-dependently decreased oxycodone self-administration during maintenance of self-administration (Fig. 1c). A two-way ANOVA with repeated measures over sessions (baseline vs. treatment) revealed significant group $\times$ session interaction $\left(F_{3,21}=11.35, \quad p<0.001\right)$. Post hoc analysis indicated that $25 \mathrm{mg} / \mathrm{kg}$ VK4-116 significantly inhibited oxycodone selfadministration as compared to the vehicle group or the preceding baseline level (Fig. 1c).

VK4-116 inhibits oxycodone-seeking during extinction when oxycodone is replaced by saline

When saline was substituted for oxycodone during extinction testing, the VK4-116 pretreatment (5 or $15 \mathrm{mg} / \mathrm{kg}$, i.p.) dosedependently inhibited oxycodone-seeking behavior (i.e., extinction responding) as demonstrated by selective decreases in responding on the active lever as opposed to responding on the inactive lever (Fig. 1d). One-way ANOVA revealed a significant treatment effect on active $\left(F_{2,20}=8.56, p<0.01\right)$, but not inactive $\left(F_{2,20}=1.12, p=0.35\right)$, lever presses.

VK4-116 does not reduce sucrose self-administration To determine whether VK4-116 also alters non-drug reinforcement, we observed the effects of VK4-116 on oral sucrose selfadministration. Figure $1 \mathrm{e}, \mathrm{f}$ show that all rats took the maximally allowed 100 sucrose deliveries (Fig. 1e) within the initial 30-60 min of the 3-h session in the presence or absence of the VK4-116 treatment (Fig. 1f). There was no difference between the vehicle and VK4-116 treatment groups in the total number of sucrose self-administration nor in the time needed for the maximal 100 deliveries $\left(F_{2,12}=1.49, p=0.264\right)$. We also compared the response rate over time (min) (Fig. 1g). One-way ANOVA for repeated measures over VK4-116 dose did not reveal a significant treatment main effect (Fig. $1 \mathrm{~g}, \mathrm{~F}_{2,12}=1.23$, $p=0.326)$.

VK4-116 pretreatment lowers the BP for oxycodone selfadministration under PR reinforcement

To determine whether D3R blockade alters motivation to seek oxycodone, we trained animals to self-administer oxycodone under PR reinforcement and tested the effects of VK4-116 on BP, an index of reward strength [9]. Figure 2a shows that systemic administration of VK4-116 significantly and dose-dependently lowered BP for oxycodone self-administration, suggesting a reduction in oxycodone reward under D3R blockade. A two-way ANOVA revealed a significant main effect of group $\left(F_{3,36}=7.73, p\right.$ $<0.001)$ and a significant time $\times$ group interaction $\left(\mathrm{F}_{3,36}=5.84, p\right.$ $<0.01$ ). Post hoc individual group analysis indicated a significant reduction in $\mathrm{BP}$ for oxycodone self-administration after $15 \mathrm{mg} / \mathrm{kg}$ or $25 \mathrm{mg} / \mathrm{kg}$ VK4-116 treatment as compared to baseline or the vehicle-treated group.

VK4-116 inhibits multiple-dose oxycodone self-administration We also examined oxycodone dose-response functions under FR1 reinforcement. Figure $2 b$ shows typical inverted U-shaped curves of oxycodone infusions earned across a full range of oxycodone doses. Pretreatment with $25 \mathrm{mg} / \mathrm{kg}$ dose of VK4-116 produced a significant reduction in oxycodone self-administration as assessed by a downward shift of the oxycodone dose-response curve (Fig. 2b, treatment main effect, $F_{1,28}=49.74, p<0.001$; dose main effect, $\mathrm{F}_{1,28}=2.88, p<0.05$; treatment $\times$ dose interaction, $F_{4,28}=$ $1.26, p>0.05$ ). Post hoc individual group comparisons revealed a significant reduction in oxycodone infusions at each oxycodone dose. We also compared the daily oxycodone intake during selfadministration maintained by different unit doses of oxycodone (Fig. 2c). A two-way ANOVA revealed significant main effects of treatment $\left(F_{1,28}=31.9, p<0.001\right)$, dose $\left(F_{1,28}=12.5, p<0.001\right)$, and treatment $\times$ dose interaction $\left(F_{4,28}=11.72, p<0.001\right)$. Post hoc testing indicated a significant reduction in oxycodone intake at the higher unit doses tested (Fig. 2c). 

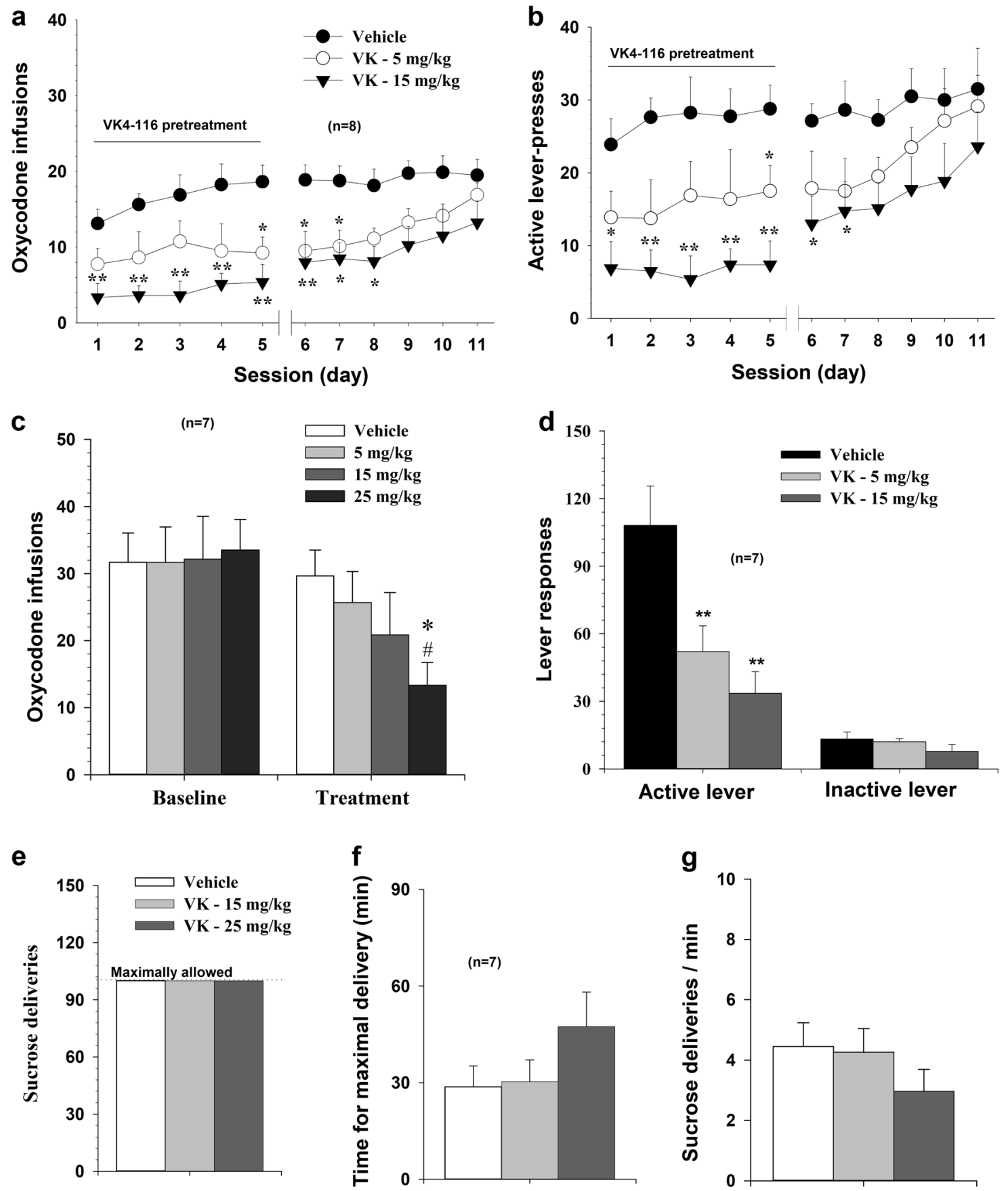

Fig. 1 Effects of VK4-116 on oxycodone- or sucrose-taking and oxycodone-seeking behavior in rats. a, b pretreatment with VK4-116 (5 or 15 $\mathrm{mg} / \mathrm{kg}$, i.p. for 5 consecutive days) dose-dependently inhibited the acquisition of oxycodone self-administration as assessed by oxycodone infusions (a) and active lever presses $(\mathbf{b})(n=8)$. c, d Pretreatments with VK4-116 $(5-25 \mathrm{mg} / \mathrm{kg}$, i.p.) also dose-dependently reduced oxycodone self-administration during the maintenance of self-administration (c) and oxycodone seeking when oxycodone was replaced by saline during self-administration (d) ( $n=6-7)$. e-g VK4-116 treatment had no effect on oral sucrose self-administration as assessed by the total number of sucrose deliveries (e), the time spent to maximal delivery (f), and the rate of sucrose deliveries $(p e r)(\mathbf{g})(n=7) .{ }^{*} p<0.05,{ }^{* *} p<0.01$, compared to vehicle group. ${ }^{\#} p<0.05$, compared to baseline

VK4-116 blocks reinstatement of oxycodone-seeking behavior Figure 3 shows the mean \pm SE responses of animals on the active and inactive levers during the last oxycodone self-administration, extinction, and reinstatement test sessions. The number of active or inactive lever presses during the last self-administration session or during the last extinction session were similar across different treatment groups. A systemic injection of oxycodone $(1 \mathrm{mg} / \mathrm{kg}$, i. p.) reinstated robust active lever presses in the vehicle-treated group, and such reinstatement was dose-dependently blocked by
VK4-116 pretreatment ( 5 or $15 \mathrm{mg} / \mathrm{kg}$ ). One-way ANOVA revealed a significant treatment main effect on the active lever presses $\left(F_{3,38}=4.38, p<0.05\right)$. VK4-116 pretreatment had no effects on inactive lever presses $\left(F_{3,38}=0.38, p>0.05\right)$.

VK4-116 does not diminish oxycodone's antinociceptive effects in rats

Baseline nociceptive response latencies ranged from $7.89 \pm 0.06$ to $8.48 \pm 0.60 \mathrm{~s}$ across all treatment groups with no significant 


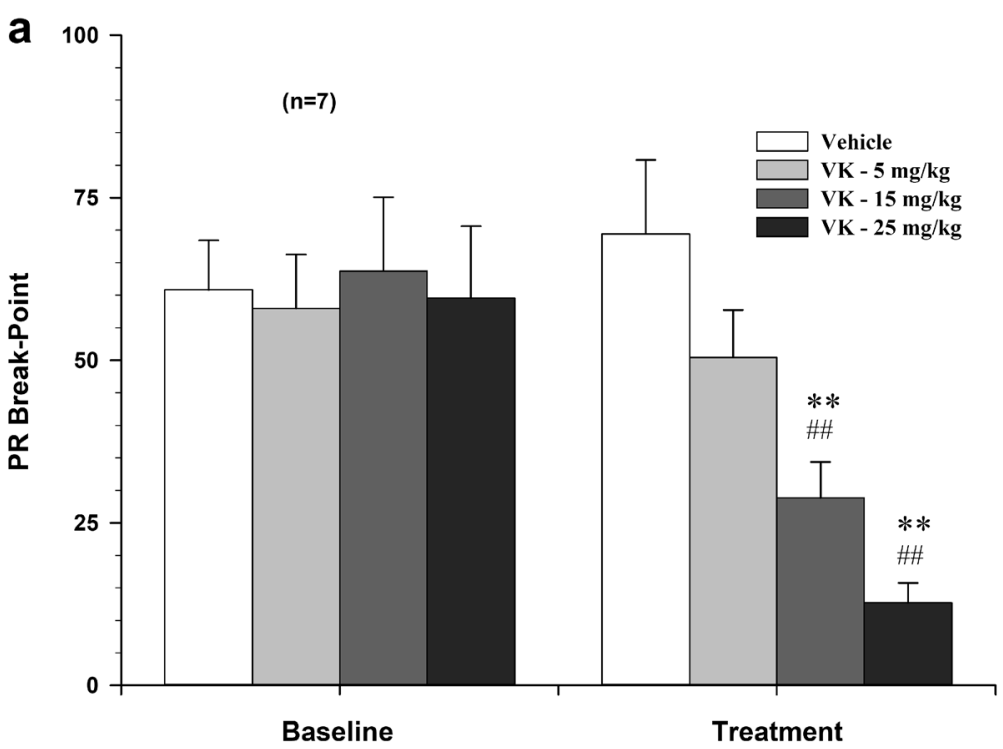

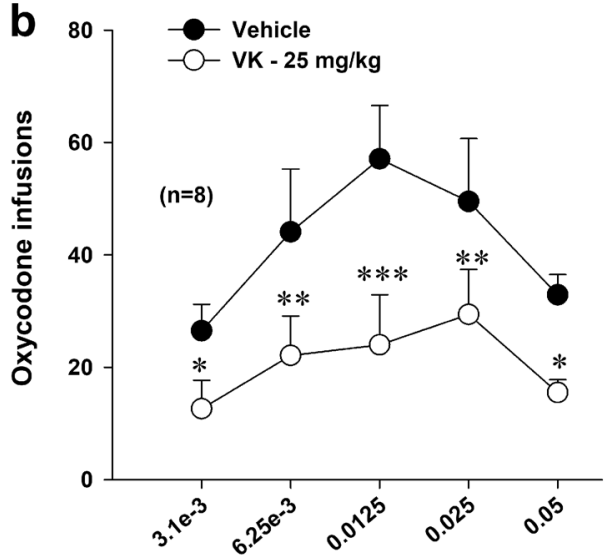

Oxycodone dose (mg/kg/infusion)

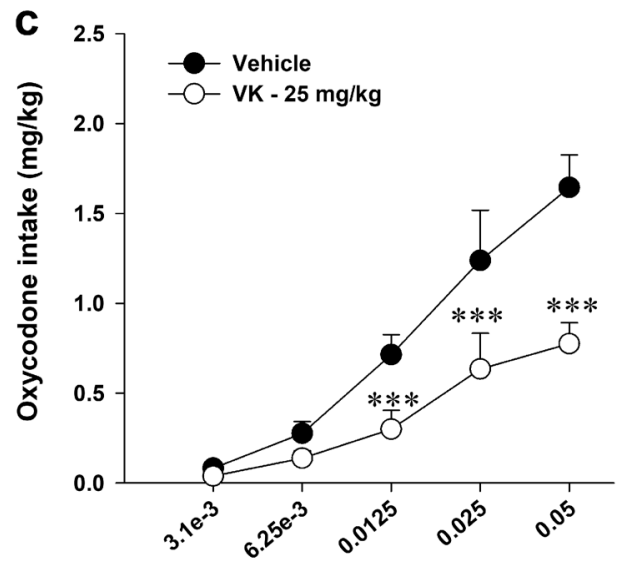

Oxycodone dose (mg/kg/infusion)

Fig. 2 Oxycodone self-administration under progressive-ratio and multiple-dose conditions. a Break-point levels for oxycodone selfadministration under PR reinforcement in the presence or absence of VK4-116. b Oxycodone dose-response self-administration function illustrating the total numbers of oxycodone infusions across five doses during daily 3 -h sessions. c Cumulative oxycodone intake at each dose. ${ }^{*} p<0.05,{ }^{* *} p<0.01,{ }^{* * *} p<0.001$ compared to vehicle group. ${ }^{\# \#} p<0.01$, compared to baseline

differences among the groups. Figure 4a shows the effects of VK4116 pretreatment on the dose-response curve of oxycodoneinduced analgesia. VK4-116 treatment produced a significant leftward shift in the oxycodone-induced analgesia dose-response curve. A two-way ANOVA revealed significant main effects of the VK4-116 treatment $\left(F_{3,25}=3.85, p<0.05\right)$ and dose $\left(F_{3,75}=230.62\right.$, $p<0.001)$, but no treatment $\times$ dose interaction $\left(F_{9,75}=0.46, p>\right.$ 0.05 ). Post hoc analysis indicated that VK4-116, at $25 \mathrm{mg} / \mathrm{kg}$, produced a significant elevation of MPE\% after 1 or $2 \mathrm{mg} / \mathrm{kg}$, but not 0.5 or $4 \mathrm{mg} / \mathrm{kg}$, oxycodone administration. Figure $4 \mathrm{~b}$ shows that VK4-116 alone (5 or $25 \mathrm{mg} / \mathrm{kg}$, i.p.) had no effect on nociceptive responses. However, pretreatment with VK4-116 dose-dependently enhanced $2 \mathrm{mg} / \mathrm{kg}$ oxycodone-induced analgesia at the 30 and 60 min test points. A two-way ANOVA revealed significant main effects of VK4-116 treatment $\left(F_{3,26}=3.60, p<\right.$ $0.05)$, and time $\left(F_{2,52}=156.71, p<0.001\right)$, but no treatment group $\times$ time interaction $\left(F_{6,52}=1.50, p>0.05\right)$.

VK4-116 inhibits naloxone-precipitated CPA

Figure $5 \mathrm{a}$ shows the experimental procedure for naloxoneprecipitated CPA. In the saline control groups, conditioning of rats with naloxone, VK4-116, or the vehicle (without oxycodone) produced neither CPP or CPA (Fig. $5 \mathrm{~b}$, left panel; $F_{2,21}=0.77$, $p>0.05)$. In rats repeatedly treated with the $3 \mathrm{mg} / \mathrm{kg}$ dose of oxycodone, naloxone challenge injections induced a significant CPA (Fig. 5b, right panel). Pretreatment with VK4-116 (5 or $15 \mathrm{mg} /$ $\mathrm{kg}$, i.p., $1 \mathrm{~h}$ prior to each naloxone injection) dose-dependently attenuated the naloxone-precipitated CPA as compared to the vehicle-treated group. A one-way ANOVA revealed a significant treatment effect $\left(F_{1,21}=7.10, p<0.01\right)$. Post hoc individual group comparisons indicated a significant reduction in the CPA score after 5 or $15 \mathrm{mg} / \mathrm{kg}$ VK4-116 administration.

VK4-116 is metabolically stable in rat, rhesus monkey, and human liver microsomes

VK4-116 was tested for species-specific phase I metabolic stability in rat, rhesus monkey, and human liver microsomes fortified with NADPH. As depicted in Fig. 6, VK4-116 showed stability in all three species ( $>50 \%$ remaining over $1 \mathrm{~h}$ ), with highest stability in rat ( $\sim 85 \%$ remaining at $1 \mathrm{~h}$ ) followed by human and rhesus monkey. The corresponding calculated half-lives were 250, 116, and 102 min in rat, human, and monkey, respectively, suggesting that VK4116 may undergo slow metabolic clearance in vivo. Notably, VK4116 was completely stable in all conditions without NADPH (that served as a negative control), confirming compound undergoing specific CYP-dependent oxidative metabolism. 

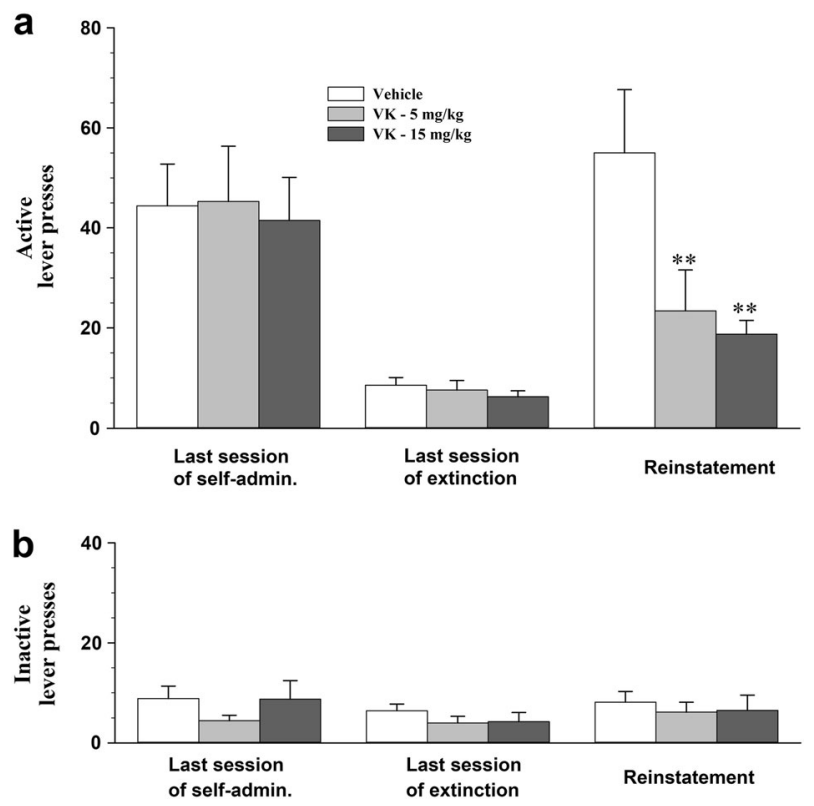

Fig. 3 Effects of VK4-116 pretreatment $(5-15 \mathrm{mg} / \mathrm{kg}$, i.p.) on reinstatement of oxycodone seeking behavior induced by a priming injection of oxycodone (1 mg/kg, i.p.). Data represent mean ( \pm S.E.M) for $N=7-8$ in each group. ${ }^{* *} p<0.01$ compared to the vehicle group

\section{DISCUSSION}

We herein demonstrate that VK4-116, a highly selective and metabolically stable D3R antagonist across species, produced the following effects: it dose-dependently attenuated the acquisition and maintenance of oxycodone self-administration under FR1 reinforcement, lowered BPs under PR reinforcement, and shifted the oxycodone self-administration dose-response curve downward. In addition. VK4-116 inhibited drug seeking during extinction and oxycodone-primed reinstatement of drug seeking. These findings suggest that VK4-116 is capable of reducing oxycodone reward and relapse. Importantly, VK4-116 pretreatment did not compromise the therapeutic analgesic effects of oxycodone. In contrast, it enhanced oxycodone analgesia in a dose-dependent manner and also alleviated naloxoneprecipitated aversive effects. These findings suggest that VK4116 (or potentially other highly selective D3R antagonists) has potential for the treatment of opioid use disorders.

The inhibitory effects of VK4-116 on oxycodone-taking and oxycodone-seeking behavior are unlikely to have been due to nonspecific motor impairment since VK4-116 treatment affected neither locomotor activity [28] nor inactive lever presses. Moreover, VK4-116, at doses that attenuated oxycodone selfadministration, failed to alter operant sucrose self-administration, as assessed by either the total number of sucrose deliveries, time spent, or the response rate. The lack of VK4116 effects on sucrose self-administration is in agreement with many previous reports using a variety of D3R antagonists $[6,20$, $23,24,35]$. Thus, the effects of VK4-116 on oxycodone selfadministration and on oxycodone seeking observed in this study are likely attributed primarily to its inhibition of oxycodoneinduced reinforcement.

D3R and opioid reward

The present findings with VK4-116 in oxycodone selfadministration are consistent with previous reports that D3R blockade by SB-277011A or other D3R antagonists significantly inhibits opioid-induced CPP in rats [11], oxycodone selfadministration in rats [24], and heroin self-administration in
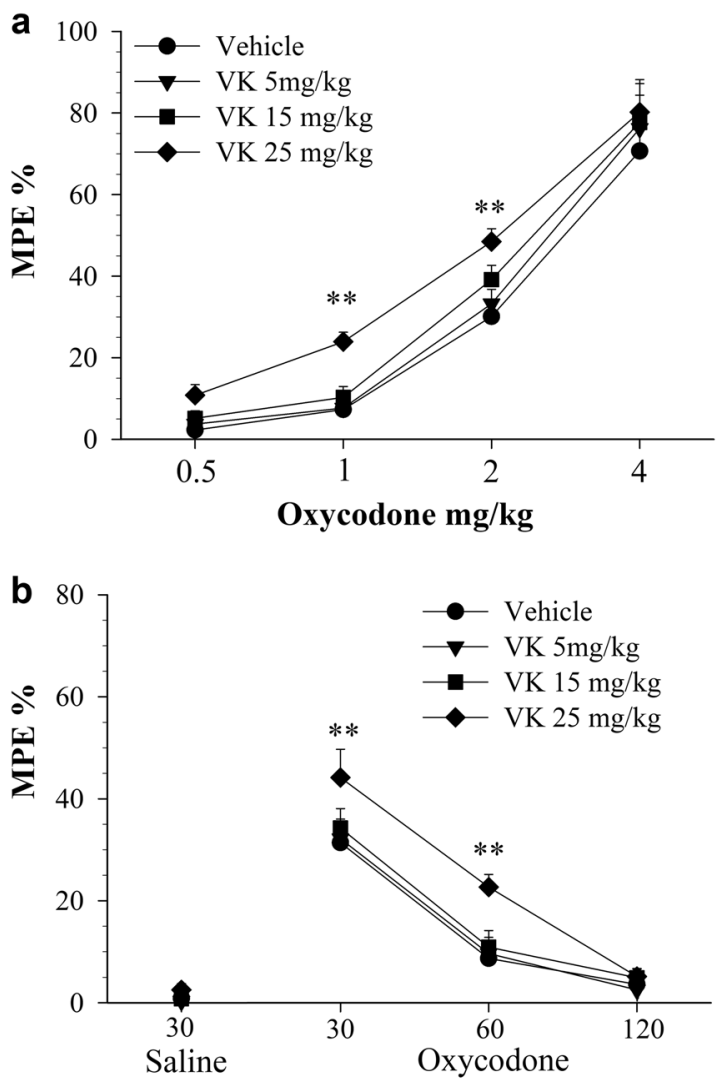

Time after injection (min)

Fig. 4 Effects of VK4-116 on the antinociceptive effects of oxycodone in rats. a VK4-116 pretreatment produced an upward or left shift in the dose-response curve of oxycodone-induced analgesia in the hot plate test. Data represent mean ( \pm S.E.M) for $n$ $=8-9$ in each group. b Time courses of $2.0 \mathrm{mg} / \mathrm{kg}$ oxycodoneinduced analgesia as assessed by the hot plate test in the absence or presence of VK4-116 pretreatment. Oxycodone dose-dependently increased MPE\% and pretreatment with VK4-116, at the $25 \mathrm{mg} / \mathrm{kg}$ dose, significantly potentiated oxycodone's analgesic effect at the 1 and $2 \mathrm{mg} / \mathrm{kg}$ doses. Data represent mean $( \pm$ SEM) for $n=8-9$ in each group. ${ }^{* *} p<0.01$ compared to the vehicle control group

wild-type mice, but not in D3R-knockout mice [36]. Deletion of D3R in D3-knockout mice also attenuates mesolimbic dopamine and locomotor responses to heroin [29]. VK4-116 also inhibits acquisition of oxycodone-induced locomotor sensitization and CPP [28].

It is well accepted that opioid reward is attributed to activation of $\mathrm{mu}$ opioid receptors located in GABAergic interneurons or GABAergic afferents in the VTA. Stimulation of these receptors suppresses GABAergic neuronal activity and consequently disinhibits DA neurons [37]. Since D3R has the highest binding affinity to DA among the five DA receptor subtypes, it is reasonable to predict that D3R blockade will attenuate effects produced by opioids. Clearly, our findings in the present study support this hypothesis. In addition, chronic administration of morphine is associated with an increase in D3R mRNA expression in the mesolimbic DA system [38]. Thus, blockade of enhanced D3R transmission by VK4-116 may also contribute to reductions in opioid-taking and opioid-seeking behavior. Taken together, D3R antagonist treatment may represent an effective add-on medication to reduce the abuse liability of prescription opioids, particularly in patients with high vulnerability to develop opioid dependence. 
a
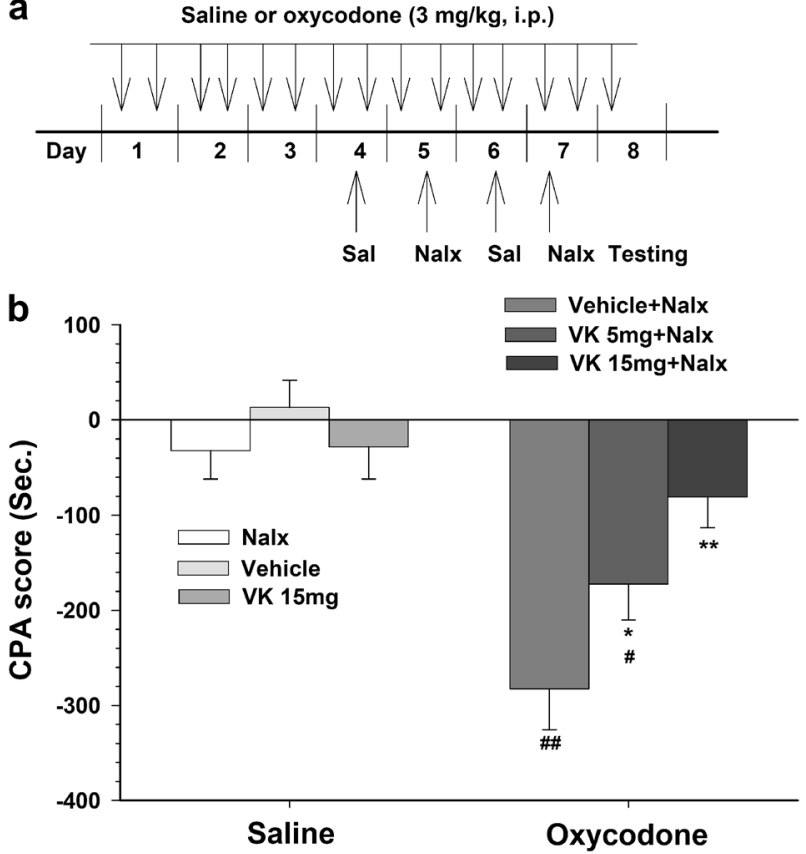

Fig. 5 Effects of VK4-116 pretreatment on naloxone-precipitated conditioned place aversion (CPA) in rats. a Schematic drawing showing the general procedure for naloxone (Nalx)-precipitated CPA; b VK4-116 administered $1 \mathrm{~h}$ prior to Nalx conditioning significantly attenuated Nalx-precipitated CPA in oxycodonetreated rats tested $24 \mathrm{~h}$ after the last conditioning session (right panel). VK4-116 or Nalx alone had no effect in saline-treated rats (left panel). ${ }^{\#} p<0.05$, \#\# $p<0.01$, compared to saline-treated group; ${ }^{*} p<$ $0.05,{ }^{* *} p<0.01$, compared to vehicle + Nalx group. Data represent means $( \pm$ SEM) for $n=8$ in each group

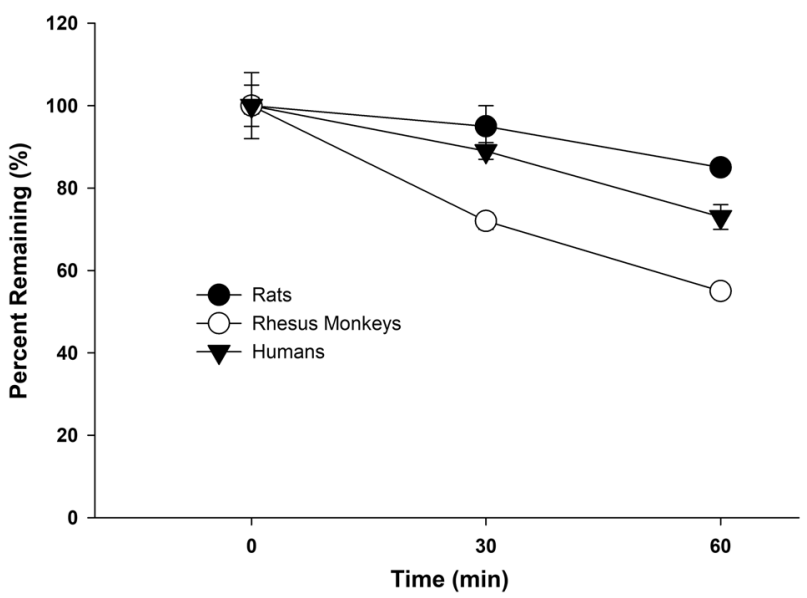

Fig. 6 Species-specific phase I metabolic stability of VK4-116 in liver microsomes from rat, rhesus monkey, and human. VK4-116 was generally stable in all thee species following incubation in liver microsomes fortified with NADPH. The general rank order for different species was rat $>$ human $>$ rhesus monkey. In all three species, the compound remained completely stable, $>95 \%$ remaining, in microsomes lacking NADPH (negative control, data not shown), suggesting that VK4-116 undergoes specific CYPdependent metabolism. Data are presented as means \pm SEM $(n=$ $3 /$ compound/time point). Buprenorphine was used as a positive control, with $<10 \%$ remaining at $60 \mathrm{~min}$ (data not shown).

D3R and opioid analgesia

Importantly, VK4-116, at doses that effectively inhibited the acquisition of oxycodone self-administration, did not compromise the antinociceptive effects of oxycodone tested in the hot plate assay. Rather, VK4-116, at the highest dose $(25 \mathrm{mg} / \mathrm{kg})$, potentiated the antinociceptive effects of oxycodone, suggesting that co-administration of VK4-116 with opioid analgesics may produce similar pain-relieving effects as are produced by higher opioid doses. This may be particularly advantageous as lower doses of opioids can be expected to have decreased unwanted side effects. Obviously, drug-induced locomotor impairment may cause an increase in antinociceptive latency, producing an artifactual analgesic effect. However, this is unlikely since VK4-116 did not produce any locomotor impairment, as previously reported (compound 19 in ref. [28]).

The mechanisms underlying D3R antagonist-induced enhancement of opioid-induced analgesia are unknown. We have previously reported that systemic administration of NGB-2904, a selective D3R antagonist, significantly enhanced cocaine-induced increases in extracellular nucleus accumbens DA, possibly via a presynaptic D3R mechanism [16]. Thus, one possibility is that D3R blockade by VK4-116 may increase extracellular DA in such painrelated brain regions as the periaqueductal gray (PAG). Given that DA-induced activation of D1 and D2 receptors in brain regions involved in pain modulation and transmission has antinociceptive effects $[39,40]$, the enhanced DA release in the PAG, or other painmodulating brain regions, may in part underlie the enhanced opioid-induced analgesia after VK4-116 administration.

D3R and opioid withdrawal

Opioid dependence can be defined, at least in part, as the presence of somatic withdrawal signs and negative motivational and affective responses upon abrupt removal of opioids from the system [41]. Growing evidence suggests that the noradrenergic locus coeruleus (LC) is a major brain site involved in the onset of opioid withdrawal [41, 42]. Neurons in the LC possess a high density of $\mu$ opioid receptors (MORs) [43]. When opioids bind to MORs in the LC, they suppress neuronal activity by inhibiting adenylyl cyclase-resulting in physical symptoms such as drowsiness, slow respiration, and low blood pressure [42]. When opioids are continuously present, their suppressive impact is offset by progressive tolerance to opioid-induced inhibition of adenylyl cyclase. When opioids are withdrawn, LC neurons release excessive noradrenaline, producing withdrawal symptoms such as anxiety, muscle cramping, and diarrhea [41, 42]. Such withdrawal symptoms are often seen in subjects after cessation of chronic high-dose opioid administration.

In the present self-administration experiments, we used very low oxycodone doses in self-administration $(0.003-0.05 \mathrm{mg} / \mathrm{kg} /$ infusion with an accumulative oxycodone dose $<2 \mathrm{mg} / \mathrm{kg} /$ day within $3 \mathrm{~h}$ ) and there were no apparent withdrawal signs observed in the rats during extinction or abstinence. We therefore used a different low opioid dose regimen to observe naloxoneprecipitated CPA [30, 31] (see Fig. 5a). In this behavioral model, we did not observe significant somatic withdrawal signs, but observed robust CPA, an index of negative motivational and affective response, after naloxone challenge. Strikingly, VK4-116 pretreatment significantly attenuated naloxone-precipitated CPA in chronic oxycodone-treated rats in a dose-dependent manner, suggesting that D3R antagonists may be useful in reducing opioid physical dependence during withdrawal periods. This is consistent with a previous report that SB-277011A, another D3R antagonist, also blocked naloxone-precipitated CPA in chronic morphinetreated rats [44]. Clearly, more studies are required to determine whether D3R antagonists may be effective at reducing somatic withdrawal signs after termination of high-dose opioid use.

In summary, the present study indicates that VK4-116 not only inhibits opioid reward, but also attenuates the aversive or stresslike state induced by naloxone-precipitated withdrawal. Aversive or stress-like states arising from drug withdrawal are considered to be major factors that drive compulsive drug taking and seeking in 
addicts [45, 46]. In addition, VK4-116 is also effective at reducing reinstatement of drug seeking trigged by oxycodone priming. VK4-116 has a stable metabolic profile across species. This metabolic stability distinguishes VK4-116 from many previously described D3R ligands and suggests high translational potential [26]. Together, our findings indicate that VK4-116 may be a promising pharmacotherapeutic agent for treating opioid dependence at various stages, including prevention of initial abuse, and treatment during detoxification and relapse. Further evaluation of VK4-116's therapeutic utility is underway in studies with nonhuman primates.

\section{FUNDING AND DISCLOSURE}

This research was supported by NIDA-IRP (Z1A DA000424). None of the authors have any disclosures. AHN and VK are co-inventors on an NIH patent that covers VK4-116 and has been licensed. All rights are reserved by $\mathrm{NIH}$.

\section{AUTHOR CONTRIBUTIONS}

$Z-X X$ and AHN designed the experiments. Z-B Y, G-HB and EG performed the behavioral experiments. VK and JC synthesized VK4-116. AG, RR, and BS performed the metabolic assays. Z-BY, AG, RR, and Z-XX analyzed the data and prepared the figures. $Z-B Y, Z-X X$, and $A H N$ wrote the manuscript. ELG edited an earlier version of the manuscript.

\section{REFERENCES}

1. Compton WM, Jones CM, Baldwin GT. Relationship between nonmedical prescription-opioid use and heroin use. N Engl J Med. 2016;374:154-63.

2. Kenan K, Mack K, Paulozzi L. Trends in prescriptions for oxycodone and other commonly used opioids in the United States, 2000-2010. Open Med. 2012;6:e41-47.

3. Meyer R, Patel AM, Rattana SK, Quock TP, Mody SH. Prescription opioid abuse: a literature review of the clinical and economic burden in the United States. Popul Health Manag. 2014;17:372-87.

4. Cerda M, Santaella J, Marshall BD, Kim JH, Martins SS. Nonmedical prescription opioid use in childhood and early adolescence predicts transitions to heroin use in young adulthood: a national study. J Pediatr. 2015;167:605-12. e601-602

5. Jones $C M$, Einstein EB, Compton WM. Changes in synthetic opioid involvement in drug overdose deaths in the United States, 2010-216. JAMA. 2018;319:1819-21.

6. Heidbreder CA, Newman AH. Current perspectives on selective dopamine $D(3)$ receptor antagonists as pharmacotherapeutics for addictions and related disorders. Ann NY Acad Sci. 2010;1187:4-34.

7. Sokoloff $\mathrm{P}$, Le Foll B. The dopamine D3 receptor, a quarter century later. Eur J Neurosci. 2017;45:2-19.

8. Ross JT, Corrigall WA, Heidbreder CA, LeSage MG. Effects of the selective dopamine D3 receptor antagonist SB-277011A on the reinforcing effects of nicotine as measured by a progressive-ratio schedule in rats. Eur J Pharmacol. 2007;559:173-9.

9. Xi ZX, Gilbert JG, Pak AC, Ashby CR Jr., Heidbreder CA, Gardner EL. Selective dopamine D3 receptor antagonism by SB-277011A attenuates cocaine reinforcement as assessed by progressive-ratio and variable-costvariable-payoff fixed-ratio cocaine self-administration in rats. Eur J Neurosci. 2005;21:3427-38.

10. Micheli F, Bonanomi G, Blaney FE, Braggio S, Capelli AM, Checchia A, et al. 1,2,4Triazol-3-yl-thiopropyl-tetrahydrobenzazepines: a series of potent and selective dopamine $D(3)$ receptor antagonists. J Med Chem. 2007;50:5076-89.

11. Ashby CR Jr., Paul M, Gardner EL, Heidbreder CA, Hagan JJ. Acute administration of the selective D3 receptor antagonist SB-277011A blocks the acquisition and expression of the conditioned place preference response to heroin in male rats. Synapse. 2003;48:154-6.

12. Song $R$, Zhang $H Y$, Peng $X Q$, Su RB, Yang RF, Li J, et al. Dopamine $D(3)$ receptor deletion or blockade attenuates cocaine-induced conditioned place preference in mice. Neuropharmacology. 2013;72:82-87.

13. Aujla $H$, Beninger RJ. The dopamine $D(3)$ receptor-preferring partial agonist BP 897 dose-dependently attenuates the expression of amphetamine-conditioned place preference in rats. Behav Pharmacol. 2005;16:181-6.

14. Vorel SR, Ashby CR Jr., Paul M, Liu X, Hayes R, Hagan JJ, et al. Dopamine D3 receptor antagonism inhibits cocaine-seeking and cocaine-enhanced brain reward in rats. J Neurosci. 2002;22:9595-603.
15. Andreoli M, Tessari M, Pilla M, Valerio E, Hagan JJ, Heidbreder CA. Selective antagonism at dopamine D3 receptors prevents nicotine-triggered relapse to nicotine-seeking behavior. Neuropsychopharmacology. 2003;28:1272-80.

16. Xi ZX, Gardner EL. Pharmacological actions of NGB 2904, a selective dopamine D3 receptor antagonist, in animal models of drug addiction. CNS Drug Rev. 2007;13:240-59.

17. Xi ZX, Gilbert J, Campos AC, Kline N, Ashby CR Jr., Hagan JJ, et al. Blockade of mesolimbic dopamine D3 receptors inhibits stress-induced reinstatement of cocaine-seeking in rats. Psychopharmacology (Berl). 2004;176:57-65.

18. Galaj E, Manuszak M, Babic S, Ananthan S, Ranaldi R. The selective dopamine D3 receptor antagonist, SR 21502, reduces cue-induced reinstatement of heroin seeking and heroin conditioned place preference in rats. Drug Alcohol Depend. 2015;156:228-33.

19. Gilbert JG, Newman AH, Gardner EL, Ashby CR Jr., Heidbreder CA, Pak AC, et al. Acute administration of SB-277011A, NGB 2904, or BP 897 inhibits cocaine cueinduced reinstatement of drug-seeking behavior in rats: role of dopamine D3 receptors. Synapse. 2005;57:17-28.

20. Higley AE, Kiefer SW, Li X, Gaal J, Xi ZX, Gardner EL. Dopamine D(3) receptor antagonist SB-277011A inhibits methamphetamine self-administration and methamphetamine-induced reinstatement of drug-seeking in rats. Eur J Pharmacol. 2011;659:187-92.

21. Pak AC, Ashby CR Jr., Heidbreder CA, Pilla M, Gilbert J, Xi ZX, et al. The selective dopamine D3 receptor antagonist SB-277011A reduces nicotine-enhanced brain reward and nicotine-paired environmental cue functions. Int J Neuropsychopharmacology. 2006;9:585-602.

22. Spiller $K, X i$ ZX, Peng $X Q$, Newman AH, Ashby CR Jr., Heidbreder $C$, et al. The selective dopamine D3 receptor antagonists SB-277011A and NGB 2904 and the putative partial D3 receptor agonist BP-897 attenuate methamphetamineenhanced brain stimulation reward in rats. Psychopharmacology (Berl). 2008;196:533-42.

23. Xi ZX, Newman AH, Gilbert JG, Pak AC, Peng XQ, Ashby CR Jr., et al. The novel dopamine D3 receptor antagonist NGB 2904 inhibits cocaine's rewarding effects and cocaine-induced reinstatement of drug-seeking behavior in rats. Neuropsychopharmacology. 2006;31:1393-405.

24. You ZB, Gao JT, Bi GH, He Y, Boateng C, Cao J, et al. The novel dopamine D3 receptor antagonists/partial agonists CAB2-015 and BAK4-54 inhibit oxycodonetaking and oxycodone-seeking behavior in rats. Neuropharmacology. 2017;126:190-9.

25. Clement P, Pozzato C, Heidbreder C, Alexandre L, Giuliano F, Melotto S. Delay of ejaculation induced by SB-277011, a selective dopamine D3 receptor antagonist, in the rat. J Sex Med. 2009;6:980-8.

26. Keck TM, John WS, Czoty PW, Nader MA, Newman AH. Identifying medication targets for psychostimulant addiction: unraveling the dopamine D3 receptor hypothesis. J Med Chem. 2015;58:5361-80.

27. Appel NM, Li SH, Holmes TH, Acri JB. Dopamine D3 receptor antagonist (GSK598809) potentiates the hypertensive effects of cocaine in conscious, freelymoving dogs. J Pharmacol Exp Ther. 2015;354:484-92.

28. Kumar V, Bonifazi A, Ellenberger MP, Keck TM, Pommier E, Rais R, et al. Highly selective dopamine $\mathrm{D} 3$ receptor (D3R) antagonists and partial agonists based on eticlopride and the D3R Crystal structure: new leads for opioid dependence treatment. J Med Chem. 2016;59:7634-50.

29. Zhan J, Jordan CJ, Bi GH, He XH, Gardner EL, Wang YL, et al. Genetic deletion of the dopamine D3 receptor increases vulnerability to heroin in mice. Neuropharmacology. 2018;141:11-20.

30. Olmstead MC, Burns LH. Ultra-low-dose naltrexone suppresses rewarding effects of opiates and aversive effects of opiate withdrawal in rats. Psychopharmacology (Berl). 2005;181:576-81.

31. Azar MR, Jones BC, Schulteis G. Conditioned place aversion is a highly sensitive index of acute opioid dependence and withdrawal. Psychopharmacology (Berl). 2003;170:42-50.

32. Lemberg K, Kontinen VK, Viljakka K, Kylanlahti I, Yli-Kauhaluoma J, Kalso E. Morphine, oxycodone, methadone and its enantiomers in different models of nociception in the rat. Anesth Analg. 2006;102:1768-74.

33. Poyhia R, Kalso EA. Antinociceptive effects and central nervous system depression caused by oxycodone and morphine in rats. Pharmacol Toxicol. 1992;70:125-30.

34. Baranczewski P, Stanczak A, Sundberg K, Svensson R, Wallin A, Jansson J, et al. Introduction to in vitro estimation of metabolic stability and drug interactions of new chemical entities in drug discovery and development. Pharmacol Rep. 2006;58:453-72.

35. Song R, Yang RF, Wu N, Su RB, Li J, Peng XQ, et al. YQA14: a novel dopamine D3 receptor antagonist that inhibits cocaine self-administration in rats and mice, but not in D3 receptor-knockout mice. Addict Biol. 2012;17:259-73.

36. Boateng CA, Bakare OM, Zhan J, Banala AK, Burzynski C, Pommier E, et al. High affinity dopamine $\mathrm{D} 3$ receptor (D3R)-selective antagonists attenuate heroin self- 
administration in wild-type but not D3R knockout mice. J Med Chem. 2015;58:6195-213.

37. Fields HL, Margolis EB. Understanding opioid reward. Trends Neurosci. 2015;38:217-25.

38. Spangler R, Goddard NL, Avena NM, Hoebel BG, Leibowitz SF. Elevated D3 dopamine receptor mRNA in dopaminergic and dopaminoceptive regions of the rat brain in response to morphine. Brain Res Mol Brain Res. 2003;111:74-83.

39. Magnusson JE, Fisher K. The involvement of dopamine in nociception: the role of $D(1)$ and $D(2)$ receptors in the dorsolateral striatum. Brain Res. 2000;855:260-6.

40. Meyer PJ, Morgan MM, Kozell LB, Ingram SL. Contribution of dopamine receptors to periaqueductal gray-mediated antinociception. Psychopharmacology (Berl). 2009;204:531-40.

41. Rehni AK, Jaggi AS, Singh N. Opioid withdrawal syndrome: emerging concepts and novel therapeutic targets. CNS Neurol Disord Drug Targets. 2013;12:112-25.
42. Kosten TR, George TP. The neurobiology of opioid dependence: implications for treatment. Sci Pract Perspect. 2002;1:13-20.

43. Jaremko KM, Thompson NL Jr., Reyes BA, Jin J, Ebersole B, Jenney CB, et al. Morphine-induced trafficking of a mu-opioid receptor interacting protein in rat locus coeruleus neurons. Prog Neuropsychopharmacol Biol Psychiatry. 2014;50:53-65.

44. Rice OV, Gardner EL, Heidbreder CA, Ashby CR Jr.. The acute administration of the selective dopamine $\mathrm{D}(3)$ receptor antagonist SB-277011A reverses conditioned place aversion produced by naloxone precipitated withdrawal from acute morphine administration in rats. Synapse. 2012;66:85-87.

45. Koob GF, Mason BJ. Existing and future drugs for the treatment of the dark side of addiction. Annu Rev Pharmacol Toxicol. 2016;56:299-322.

46. Koob GF, Volkow ND. Neurobiology of addiction: a neurocircuitry analysis. Lancet Psychiatry. 2016;3:760-73. 